\title{
Manufacturing and Production Economics Numerical Model Old Non-FMS versus Modern FMS Plants
}

\author{
Gerald Aranoff \\ Ariel University, Ariel, Israel \\ Email: garanoff@netvision.net.il
}

How to cite this paper: Aranoff, G. (2019) Manufacturing and Production Economics Numerical Model Old Non-FMS versus Modern FMS Plants. Modern Economy, 10, 2387-2392.

https://doi.org/10.4236/me.2019.1012150

Received: November 5, 2019

Accepted: December 24, 2019

Published: December 27, 2019

Copyright $\odot 2019$ by author(s) and Scientific Research Publishing Inc. This work is licensed under the Creative Commons Attribution International License (CC BY 4.0).

http://creativecommons.org/licenses/by/4.0/

\section{(c) (i) Open Access}

\begin{abstract}
Flexible Manufacturing System (FMS) is a modern innovation in manufacturing technology that allows a factory to switch at no cost between manufacturing different products. This paper presents a simple numerical model of manufacturing and production economics with illustrated demand and cost curves. The model shows industry long-run equilibrium $(E(\pi)=0)$ for manufacturing and production to supply hypothetical demand schedules for two products: 1 and 2. The model has two plant types: old non-FMS Plant ${ }_{2 L}$ that can produce only product 2 and modern FMS Plant ${ }_{K}$ that can switch easily between manufacturing products 1 and 2 . The model assumes linear total cost curves with absolute capacity limits for the two plant types.
\end{abstract}

\section{Keywords}

Flexible Manufacturing System

\section{Introduction}

\subsection{Manufacturing and Production}

Manufacturing is the transformation of raw materials into new products. Statistics show the importance of manufacturing and production in the US ${ }^{1}$ :

Manufacturing is an essential component of gross domestic product, which was $\$ 2.33$ trillion in 2018 , and drove $11.6 \%$ of US economic output, according to the Bureau of Economic Analysis. Manufactured goods comprise half of US exports. Manufacturing adds a lot of value to the power of the US economy. Every dollar spent in manufacturing adds $\$ 1.89$ in business

'https://www.thebalance.com/u-s-manufacturing-what-it-is-statistics-and-outlook-3305575. 
growth in other supporting sectors, including retailing, transportation, and business services. According to the Bureau of Labor Statistics, the United States has 12.85 million manufacturing jobs, which employs $8.5 \%$ of the workforce, and pays $12 \%$ more than other jobs.

\subsection{Percent Capacity Utilization: Generally Low}

Today we experience world-wide technological revolutions, political upheavals, trade wars, and financial crises. World economies generally operate today below long-run average rates for capacity utilization.

US reports on capacity utilization for manufacturing are shown in Table $1^{2}$.

\subsection{The Flexible Manufacturing System: Surviving Trade Wars and Technology Revolutions}

A flexible manufacturing system allows the system to react to changes, whether predicted or unpredicted. This flexibility falls into two categories. The first category, routing flexibility, covers the system's ability to produce new product types and change the order of operations executed on a part. The second category is called machine flexibility, which is the ability to use multiple machines to perform the same operation on a part, as well as the system's ability to absorb large-scale changes, such as in volume or capability. In my simple numerical example of flexible versus inflexible manufacturing system, $K$ versus $L, K$ is the flexible manufacturing system that can easily switch from making Product 1 to making Product 2 and visa versa. $\mathrm{L}$ is the inflexible manufacturing system that manufactures only Product 2.

The flexible manufacturing system is an exciting new development in manufacturing technology, allowing switching easily between products manufactured. Researchers in production and manufacturing praise the flexible manufacturing system $^{3}$. My numerical example convincingly demonstrates the superiority of the flexible manufacturing system.

\subsection{A World of Globalization}

I wrote recently about today's world of globalization. I write ${ }^{4}$ :

Globalization is a process of interaction and integration among the people, companies, and governments of different nations, a process driven by international trade and investment and aided by information technology.

Table 1. The US reports capacity utilization for manufacturing.

\begin{tabular}{cccc}
\hline $1972-2018$ & $1994-1995$ & 2009 & October 2019 \\
\hline $78.2 \%$ & $84.7 \%$ & $63.5 \%$ & $75.2 \%$ \\
average & high & low & latest \\
\hline
\end{tabular}

${ }^{2}$ https://www.federalreserve.gov/releases/g17/current/table7.htm.

${ }^{3}$ See Chan et al. [1].

${ }^{4}$ Aranoff, Gerald, "Globalization: Alternative Pricing in a Peak-Load Pricing Model," Modern Economy, 8 July 2017 [2]. 
Globalization increases under open-market systems domestically and internationally. Countries under open-market systems have large numbers of producers and buyers of goods and services each acting to his/her interest to secure profits and consumer welfare with minimal government interferrence/regulation.

With globalization today, there is an urgent need for flexible manufacturing systems, whereby factories can easily switch making Product 1 to Product 2 to

Product 3 , and so on.

\section{Numerical Example}

\subsection{Old Non-FMS Plant ${ }_{2 L}$ versus Modern FMS Plant ${ }_{K}$}

In my numerical example, for simplification, I assume the demand schedules for product 1 and for product 2 are identical except for the frequency of the occurrence, $w$. At times of $w_{1}$ there is demand only for product 1 and no demand for product 2. At times of $w_{2}$ there is demand for product 2 and no demand for product 1 .

$$
\begin{aligned}
& P_{1}=3456 / Q_{1} w_{1} \\
& P_{2}=3456 / Q_{2} w_{2}
\end{aligned}
$$

I assume that the modern FMS plant ${ }_{K}$ has lower variable cost (VC) per unit and higher fixed cost (FC) per period than the Old non-FMS plant ${ }_{2 L}$. Modern FMS plants have the latest robots and computerized production equipment making them capital intensive. Old non-FMS plants have durable and specific assets with low FC and operate as standby capacity to meet peak demand periods. The model assumes, for simplicity, that the modern FMS plant has the same VC and FC, for products 1 and 2. The assumption is that products 1 and 2 use raw materials that cost the same and that the production process is the same or similar.

\subsection{The Industry of Manufacturing Product 1 and Product 2}

Investors seeking to invest in manufacturing and production of product 1 and product 2 can choose between two hypothetical plants, modern FMS plant $K_{K}$ and Old non-FMS plant $2 L$. Both plants have durable specific assets and linear short-run total costs curves with absolute capacity limits. The plants differ in per-unit variable cost, $(b)$, per-unit fixed cost, $(\beta)$, and capacity per plant, $(q)$. My notation is that $b$ is the constant per-unit variable operating cost. $\beta$ is the per-unit fixed capacity cost where the numerator is the constant fixed costs per week and the denominator is the maximum the plant can produce in a week. I assume periods of a week. I assume $q$ is the operating rate in a week. Let $n$ be the number of plants, a continuous variable.

I assume $b_{K}<b_{L}, \beta_{K}>\beta_{L}$, and $q_{L}>q_{K}{ }^{5}$. In my model, investors can order any number of plants ${ }_{K}$ or plants ${ }_{L}$. Plant ${ }_{K}$ has the lean accounting system which

${ }^{5}$ As in my Economic Modelling article [3]. 
lowers its $b$. Plant ${ }_{K}$ requires more fixed assets for the same output which raises its $\beta$ and lowers its $q$ for the same investment amount, say $\$ 1,000,000$. Investors cannot choose a mixture of plant $_{K}$ and plant .

For simplification, the industry will be comprised of only plants ${ }_{K}$ or only plants $_{L}$. If investors could choose a mixture of plant ${ }_{K}$ and plant ${ }_{L}$, then plant $_{K}$ would dominate.

Demand fluctuates between $P_{1}$ with frequency $w_{1}$ and $P_{2}$ with frequency $w_{2}$.

Expected total revenues $=E(T R)=P_{1} Q_{1} w_{1}+P_{2} Q_{2} w_{2}$.

Expected total costs $=E(T C)=b_{K}\left(Q_{1} w_{1}+Q_{2} w_{2}\right)+\beta_{K}\left(Q_{1}+Q_{2}\right)$.

Expected profits $=E(\pi)=E(T R)-E(T C)$.

Long-run equilibrium requires: $E(\pi)=0$.

For simplification in my numerical example, let:

$b_{1 K}=\$ 24$ per ton $_{1}=b_{2 K}=\$ 24$ per ton 2

$\beta_{1 K}=\$ 12$ per ton t $_{1}=\beta_{2 K}=\$ 12$ per ton 2

$q_{1 K}=0.72$ ton $_{1}$ per week $=q_{2 K}=0.72$ ton $_{2}$ per week

$b_{2 L}=\$ 31.2$ per ton 2

$\beta_{2 L}=\$ 4.8$ per ton 2

$q_{2 L}=0.9$ ton $_{2}$ per week

$w_{1}=w_{2}=0.5$

$P_{1}=3456 / Q_{1} w_{1}$

$P_{2}=3456 / Q_{2} w_{2}$

Plant $_{K}$ illustrates flexible manufacturing system because it can switch between

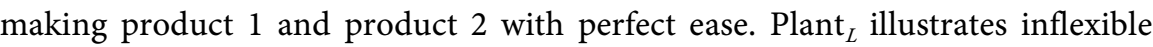
manufacturing system because it can make only product 2. Plant ${ }_{L}$ shuts down temporarily in $w_{1}$ when there is no demand for product 2. Fractional plants are permitted. No long-run economies of scale are assumed for each plant. Plant ${ }_{K}$ will dominate all the more in real-world cases, because it can switch among more than two products.

Figure 1 shows an industry with all inflexible manufacturing system plants

\begin{tabular}{|lr|}
\hline Let $w_{2}=$ & 0.5 \\
$S T C_{2 L}=b_{2 L} q_{i}+\beta_{2 L} q_{2 L}$ & \\
$b_{2 L}=$ & $\$ 31.2$ per ton \\
$\beta_{2 L}=$ & $\$ 4.8$ per ton 2 \\
$q_{2 L}=$ & 0.9 tons $_{2}$ per week \\
$F C_{2 L}=\beta_{2 L} \times q_{2 L}=$ & $\$ 4.32$ per week \\
$\mathrm{SAC}(\min )_{2 L}=$ & $\$ 36$ per ton 2 \\
$P_{2}=b_{2 L}+\beta_{2 L} / w_{2}=$ & $\$ 40.8$ per ton 2 \\
$Q_{2}=$ & 84.7 tons 2 per week \\
$n_{2 L}=$ & 53.09 plants $2 L$ \\
$E(T R)_{2 L}=P_{2} Q_{2} w_{2}=$ & $\$ 1728$ \\
$E(T C)_{2 L}=b_{2 L} Q_{2} w_{2}+\beta_{2 L} Q_{2}=$ & $\$ 1728$ \\
$E(\pi)_{2 L}=$ & $\$ 0$ \\
\hline
\end{tabular}

Figure 1. LR Equil. Old non-FMS Plant ${ }_{2 L}$ and $\mathrm{D}_{2} w_{2}$. 
manufacturing product 2. The industry capacity is 84.7 tons $_{2}$ per week from 53.09 plants $_{2 L}$. Long run equilibrium exists because industry demand for product 2 is satisfied and expected profits over the cycle are zero.

Figure 2 shows an industry with all flexible manufacturing system plants ${ }_{K}$. Plants $_{K}$ can choose to manufacture product 1 or product 2 . If plants choose to make only product 1 , capacity is 84.7 tons $_{1}$ week using 117.65 plants $_{1 K}$. If plants pla choose to make only product 2 , capacity, is 84.7 tons $_{2}$ per week using 117.65 plants $_{2 K}$.

\section{Conclusion and Policy Implication}

\subsection{A Quantum Leap Forward in Manufacturing}

Flexible manufacturing systems are a quantum leap forward in manufacturing. My earlier work on output-flexibility ${ }^{6}$ presumes old-fashioned factories as in John M. Clark's ${ }^{7}$ days. Investors will want to invest in plant capacity that has a flexible manufacturing system that will enable the factory to operate at a higher rate of utilization.

\subsection{Automobile Manufacturing Facing Uncertainty}

A recent WSJ article highlights uncertainty for automobile manufacturing ${ }^{8}$.

$$
\begin{array}{|lr|}
\hline \text { Let } \mathrm{P}_{1}=3456 / Q_{1} w_{1} & \\
\text { Let } w_{1}= & 0.5 \\
\text { Let } \mathrm{P}_{2}=3456 / Q_{2} w_{2} & \\
\text { Let } w_{2}= & 0.5 \\
b_{1 K}=b_{2 K}= & \$ 24 \text { per ton } \\
\beta_{1 K}=\beta_{2 K}= & \$ 12 \text { per ton } \\
q_{1 K}=q_{2 K}= & 0.72 \text { tons per week } \\
F C_{1 K}=\beta_{1 K} Q_{1}=F C_{2 K}=\beta_{2 K} Q_{2} & \$ 8.64 \text { per week } \\
\mathrm{SAC}(\min )_{1 K}=\mathrm{SAC}(\min )_{2 K}= & \$ 36 \text { per ton } \\
P_{1}=P_{2}= & \$ 40.8 \text { per ton } \\
Q_{1}=Q_{2}= & 84.7 \text { tons per week } \\
n_{K}= & 117.65 \text { plants } \\
E(T R)_{K}=P_{1} Q_{1} w_{1}+P_{2} Q_{2} w_{2}= & \$ 1728 \\
E(T C)_{K}=b_{K}\left(Q_{1} w_{1}+Q_{2} w_{2}\right)+\beta_{K}\left(Q_{1}+Q_{2}\right)= & \$ 1728 \\
E(\pi)_{K}= & \$ 0 \\
\hline
\end{array}
$$

Figure 2. LR Equil. Modern FMS Plant $K_{K}$ and $\mathrm{D}_{1} w_{1}, \mathrm{D}_{2} w_{2}$.

${ }^{6}$ Aranoff, Gerald, "Competitive manufacturing with fluctuating demand and diverse technology: mathematical proofs and illuminations on industry output-flexibility," Economic modelling vol, 28 May 2011 1441-1450 [3].

${ }^{7}$ See John M. Clark studies in the economics of overhead costs, The University of Chicago Press, Chicago, 1923 Chapter 9 detailed data of an imaginary plant [4].

${ }^{8}$ https://www.wsj.com/articles/automobile-woes-cast-cloud-over-eastern-europe-11574607781. 
"But as with many countries in central and eastern Europe, that reliance on auto making to drive growth may become a problem as the industry slows globally and faces big changes in demand and technology. The result was a fourfold increase in the number of vehicles manufactured in central and eastern Europe over the past two decades."

Yes the global automobile industry is experiencing a slowdown. Cars are lasting longer and people are using ride sharing and other alternate transportation systems. I say, see what else car manufacturing plants could manufacture with their plants and staff. The global demand for cars may go back up, with technology improvements, rising global wealth everywhere and declining prices of cars.

\subsection{More Complex Computer Models Needed}

My simple numerical example can help companies make complex computer models of proposed plant expansion, construction, or renovation. Today, with globalization and intense worldwide competition, and technological developments, there is much uncertainty on exactly which products a company should make. Computer models will aid decision making. The flexible manufacturing system may justify capital expenditures where an inflexible manufacturing system could not be justified. Companies must have a flexible manufacturing system to prosper.

\section{Conflicts of Interest}

The author declares no conflicts of interest regarding the publication of this paper.

\section{References}

[1] Chan, F.T.S., Bhagwat, R. and Wadhwa, S. (2008) Comparative Performance Analysis of a Flexible Manufacturing System (FMS): A Review-Period-Based Control. International Journal of Production Research, 46, 1-24. https://doi.org/10.1080/00207540500521188

[2] Aranoff, G. (2017) Globalization: Alternative Pricing in a Peak-Load Pricing Model. Modern Economy, 8, 888-896. https://doi.org/10.4236/me.2017.87062

[3] Aranoff, G. (2011) Competitive Manufacturing with Fluctuating Demand and Diverse Technology: Mathematical Proofs and Illuminations on Industry Output-Flexibility. Economic Modelling, 28, 1441--1450. https://doi.org/10.1016/j.econmod.2011.02.016

[4] Maurice, C.J. (1923) Studies in the Economics of Overhead Costs. The University of Chicago Press, Chicago. 